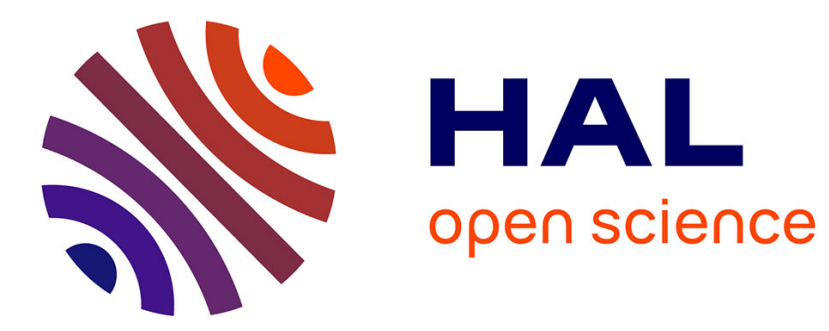

\title{
Salespeople, Fairness, and Buyer Satisfaction: What about Emotions?
}

Béatrice Siadou-Martin, David Vidal, Fanny Poujol, John Tanner

\section{To cite this version:}

Béatrice Siadou-Martin, David Vidal, Fanny Poujol, John Tanner. Salespeople, Fairness, and Buyer Satisfaction: What about Emotions?. Journal of Business to Business Marketing, 2017, 24 (3), pp.221233. 10.1080/1051712X.2017.1345261 . hal-01756955

\section{HAL Id: hal-01756955 https://hal.parisnanterre.fr/hal-01756955}

Submitted on 26 Jan 2021

HAL is a multi-disciplinary open access archive for the deposit and dissemination of scientific research documents, whether they are published or not. The documents may come from teaching and research institutions in France or abroad, or from public or private research centers.
L'archive ouverte pluridisciplinaire HAL, est destinée au dépôt et à la diffusion de documents scientifiques de niveau recherche, publiés ou non, émanant des établissements d'enseignement et de recherche français ou étrangers, des laboratoires publics ou privés. 


\section{SALESPEOPLE, FAIRNESS, AND BUYER SATISFACTION:}

\section{WHAT ABOUT EMOTION?}

Béatrice Siadou-Martin, $\mathrm{PhD}$, Professor of Marketing University of Lorraine

1 Rue Augustin Fresnel 57070 METZ

France

Tél : (033) 387378480

Fax : (033) 987378481

beatrice.siadou-martin@univ-lorraine.fr

David Vidal, PhD, Assistant Professor of Marketing

Montpellier Research in Management

Montpellier University

Place Eugène Bataillon

34095 MONTPELLIER CEDEX

France

Tél: (033) 499585140

Fax: (033) 499585056

david.vidal@univ-montp2.fr

Juliet F. Poujol, PhD, Assistant Professor of Marketing Montpellier Research in Management

INSEEC Business School Paris

Montpellier University

208 Rue Vendémiaire

34000 Montpellier

France

Tel: (033) 671828859

Fax: (033) 434432020

fpoujol@inseec.com

John F. Tanner Jr., PhD, Professor of Marketing

Strome College of Business

Old Dominion University

2008 Constant Hall

Norfolk, VA 23529

USA

Tel: (757)683-3535

jtanner@odu.edu 


\section{SALESPEOPLE, FAIRNESS, AND BUYER SATISFACTION: \\ WHAT ABOUT EMOTION?}

\section{Abstract :}

Purpose - While most studies focuses on rational decision in organizational settings, this research examines the emotional and rational dimension of the business-to-business (B2B) buying process and its influence on satisfaction through the integration of fairness and emotion theories. It thus broadens knowledge about the formation of satisfaction in buyerseller relationships, through an integration of justice and emotion theories.

Design/methodology/approach—A survey of 130 buyers was conducted. The test of the mediation model relied on structural equation modeling. To address the mediating role of positive emotions, we followed the procedure proposed by Baron and Kenny (1986). That is, we compared the proposed framework against two competing models: a non-mediated model and a saturated model that featured all possible causal paths.

Findings - The results show that positive emotions mediated the effect of fairness on satisfaction, though only partial meditation occurred between procedural fairness and satisfaction. Procedural fairness had both direct and indirect effects on satisfaction, through positive emotions.

Research limitations/implications - The findings have implications for both marketing scholars and managers. Buyers in business relationships are not completely rational, so B2B experts should acknowledge the influence of emotions in their theoretical models and sales strategies.

Practical implications - In addition to guaranteeing a "fair" outcome, sellers must ensure that buyers are subject only to fair procedures and that their salespeople generate 
positive emotions. Because buyers in business relationships are not completely rational, so B2B experts should acknowledge the influence of emotions in their sales strategies.

Originality/value-The mediating impact of emotion in the fairness-satisfaction relationship has not been explored in buyer-seller settings previously. Deconstructing satisfaction with the decision process into its cognitive and affective elements, we examine the emotional dimension of $\mathrm{B} 2 \mathrm{~B}$ buying process

Keywords : B2B relationships, emotions, justice. 
Even in their work roles, people function as humans with all of the foibles and characteristics that suggests. This reality demands investigation of such elements as the role of human emotions in business-to-business (B2B) buying situations and sales interactions (Bagozzi 2006). In contrast, most research focuses on rational decision making in organizational settings (Tanner 1999), with a few exceptions that highlight the role of emotions in B2B interactions (Andersen and Kumar 2006; Tähtinen and Blois 2011; Wang and Huff 2007). Emotions that emerge at the individual level strongly influence interactions at the interorganizational level and indicate several stimulating avenues for research (Andersen and Kumar 2006; Tähtinen and Blois 2011). For example, some studies address emotions provoked by conflict or negative experiences (Wang and Huff 2007), and others review the broader role of emotion for trust development (Andersen and Kumar 2006).

In nearly all these studies though, satisfaction appears as the outcome of a cognitive process, in which people evaluate the (dis)confirmation of their expectations (Oliver 1980). Literature on satisfaction judgments also supports both affective and cognitive components (Babin and Griffin 1998). Yet, we still need research to tease apart cognitive versus emotional reactions to buyer-seller interactions and how they lead to satisfaction. One method to deconstruct satisfaction into cognitive and affective elements is to apply the concept of fairness — or specifically, evaluative judgments of the appropriateness of the treatment a person receives (Chebat and Slusarczyk 2005) — because fairness is primarily a cognitive concept, consistent with existing (dis)confirmation models of (dis)satisfaction (Oliver 1980). What's left in determining satisfaction may be attributable to emotions. Accordingly, by deconstructing satisfaction with the decision process into its cognitive and affective elements, we can examine the emotional dimension of B2B buying process. We then study the mediating effect of positive emotions on the link between perceived fairness (distributive and procedural) and buyers' satisfaction. In the next section, we present a conceptual background 
pertaining to emotions and fairness in B2B relationships, before we detail the methodology for our quantitative study. Finally, after we discuss the results, we outline some managerial implications and research directions.

\section{Emotions in B2B relationships}

The notion of affect is a set of psychological processes and has been defined as a set of internal emotional states of positive or negative valence, which include the moods and emotions (Westbrook 1987). There is no universally accepted definition of emotions, there are generally conceptualized as mental states resulting from the assessment of an event expressed positively or negatively (Donada and Nogatchewsky 2009). Research in B-to-C show that emotions influence many aspects of consumer behaviours: Positive emotions increase consumer satisfaction while negative emotions cause the opposite effect (Westbrook 1987; Westbrook and Oliver 1991).

Although emotions are today recognized as pivotal variables in the explanation of the consumer behaviour, their influence in B-to-B has been very little studied. However, research on this subject highlight the role of affective states in the interactions between firms and show that emotions can also shape behaviour, decision-making processes and the strategies of negotiation of professional buyers (Andersen and Kumar 2006).

Unlike transactional exchanges, interorganizational relationships imply a long-term orientation and recurring interpersonal interactions across boundary spanners (Dwyer, Schurr, and Oh 1987; Ford 1982; Håkansson 1982). From an economic perspective, most research investigates how cognitive processes shape these interfirm exchanges through their rational aspects (e.g., transaction costs, power, dependence, commitment; Bagozzi 2006). With the assumption that B2B buyers are not emotional or impulsive but rather actors who make rational decisions and choices on the basis of their collective decision processes (Voss 1990), existing literature has neglected emotional factors that also can shape interorganizational 
relationships. Yet Bagozzi (2006) and Erevelles and Fukawa (2013) maintain that business relationships contain both rational (cognitive processes) and emotional (affective processes) forces. Thus, including both sets of processes is necessary to understand business relationships. Bagozzi (2006) even suggests that B2B regulatory mechanisms operate through intra-and interpersonal emotions. Andersen and Kumar (2006) further speculate that emotions, though they are individual variables, potentially affect partners' behaviors at both individual and organizational levels. Similarly, Vidal (2014) demonstrates that one specific emotion (anger) in a B2B context influences organizational behaviors. These studies, though not in the context of satisfaction, do illustrate the importance of emotions in understanding buyer behavior.

Because interorganizational relationships evolve through interaction sequences that generate specific emotions, Täthinen and Blois (2011) demonstrate that a wide range of human emotions (with the exception of love) are activated during interfirm interactions. Both positive (joy, empathy, pride, attachment, surprise) and negative (sadness, anger, fear, guilt, shame) emotions have significant consequences for participants' behavior and the relationships between their respective organizations.

Thus, research into interorganizational relationships suggests that affect, not just cognition, is a relevant study topic for the $\mathrm{B} 2 \mathrm{~B}$ marketing field and must be considered to understand the evolution of such relationships. To address understand business relationships as social interactions, we adopt a micro-level of analysis and examine both emotional and rational dimensions of business relationships.

\section{Fairness in B2B}

Kumar, Scheer, and Steenkamp (1995) noted some twenty years ago that the construct of fairness in buyer/seller relationships was ambiguous and relatively underdeveloped. Broadly, fairness reflects a person's evaluative judgment of the appropriateness of his or her 
treatment by others (Chebat and Slusarczyk 2005). Recently, research; consider four types of fairness in commercial relationships: distributive, procedural, informational and interpersonal (the last two were combined in what was first named "interactional fairness") (Duffy et al. 2013; Hoppner, Griffith, and Yeo 2014). But the concept of fairness in examinations of buyerseller relationships consists of two distinct components: distributive fairness and procedural fairness (Hoppner, Griffith, and Yeo 2014). Distributive fairness refers to the perception of how equitable the distribution of the outcomes from a relationship is relative to the inputs invested into a relationship. Procedural fairness corresponds to the perception of the fairness of the procedure followed by the partner to arrive at the decision.

Distributive fairness arose from social exchange theory, which emphasizes the role of equity for modeling subsequent interpersonal interactions. For example, channel research suggests that distributive fairness refers to the reseller's perception of the earnings and other outcomes it receives from its relationship with the supplier. Procedural fairness, in a channels setting, refers to the reseller's perception of the fairness of the supplier's procedures and processes (Kumar, Scheer, and Steenkamp 1995). In a B2B setting, customers evaluate fairness on the basis of the salesperson's behavior, and to do so, they rely on two distinct categories of fairness: distributive fairness, or the fairness of outcomes received, and procedural fairness, or the fairness of a process (Kumar, Scheer, and Steenkamp 1995).

\section{RESEARCH AND MODEL HYPOTHESES}

Satisfaction with processes explains overall customer satisfaction more effectively than do the characteristics of the product itself (Humphreys and Williams 1996). The importance of interpersonal processes and the prior research on emotions and interpersonal B2B interactions and relationships (e.g. Tähtinen and Blois 2011) suggest that buyers cannot separate emotion out of their evaluations of service quality. According to Liljander and Strandvik (1997), emotional components should be modeled as inputs to satisfaction; we 
predict specifically that emotional components mediate cognitive evaluations and therefore begin by addressing relationships between fairness and satisfaction.

In business-to-consumer (B2C) settings, the positive relationship between distributive fairness and consumer satisfaction is well established (e.g. Goodwin and Ross 1992; Tax, Brown, and Chandrashekaran 1998). Several studies also document the importance of fairness in long-term cooperation between organizations (Jap 2001), particularly as a critierion for assessing overall relationship satisfaction (Brown, Cobb, and Lusch 2006). Therefore, we hypothesize:

H1: Distributive fairness has a positive influence on a buyer's satisfaction with the selling firm, such that buyers who report higher levels of fairness also report higher levels of satisfaction.

In marketing channel literature, procedural fairness is commonly defined as a 'reseller's perception of the fairness of the supplier's procedures and processes in relation to its resellers" (Kumar, Scheer, and Steenkamp 1995, , p. 55). In a study examining the different aspects of service recovery policies, (Clemmer 1993) identifies flexibility, waiting time, and efficiency as elements of procedural fairness. Furthermore, many B2C examples reveal that procedural fairness affects post-complaint behavior, such that consumers who consider procedures and policies fair are more likely to be satisfied (e.g. Saxby, Tat, and Johansen 2000; Tax, Brown, and Chandrashekaran 1998). This relationship also has been supported in B2B settings (Brown, Cobb, and Lusch 2006; Kumar, Scheer, and Steenkamp 1995). In line with these conclusions, we hypothesize:

H2: Procedural fairness has a positive influence on the buying firm's satisfaction with the selling firm, such that when processes appear more just, satisfaction increases. Consumer research also has examined emotion in satisfaction judgments (e.g., Andreassen (2000) and Smith and Bolton (2002) suggest that emotional responses have a 
distinct influence on satisfaction judgments, even after accounting for cognitive antecedents (e.g., perceived fairness). Thus, including emotions in satisfaction models increases the amount of variance explained (Kim and Smith 2005).

Service recovery literature further implies that perceived fairness affects consumers' behavior through emotions (e.g., frustration, anger, happiness). According to Scher and Heise (1993), people do not calculate fairness but experience a fairness-related emotion and then react to it. This theoretical approach primarily is based on affect control theory (ACT), which states that people who are treated fairly experience positive emotions (Homans 1974). In a review of studies related to the effects of fairness on emotions in contexts other than service recovery, Chebat and Slusarczyk (2005) reveal that emotions are a way consumers cope with (in)fairness. Most studies concur that people who perceive the outcome as fair are "satisfied" (Hegtvedt 1990; Sprecher 1992). In bargaining situations, "the fairer individuals view their own outcome, the less likely they are to express general negative feelings and the more likely they are to express satisfaction" (Hegtvedt and Killian 1999, , p. 296).

The emotional effect of the procedural dimension of fairness is less well documented. Chebat and Slusarczyk (2005) proposed emotions as mediating the effects of fairness on customer loyalty in service recovery. Following this lead, Dayan, Al-Tamimi, and Elhadji (2008) confirmed the mediating effect of positive emotions between procedural fairness and exit or loyal consumer behavior, calling for investigations into the procedural component of fairness. Little research has done so, particularly in B2b and more importantly, in considering the relative influence of both distributive and procedural fairness. While we concur that the effects of procedural fairness should be mediated by emotions, distributive fairness may be less likely to be mediated by positive emotions. In this research we propose then to examine two paths leading to customer satisfaction: a rational path traditionally considered in B-to-B setting with distributive fairness that directly impact buyer's satisfaction; and an emotional 
path where emotion plays a mediator role between procedural fairness and buyer's

satisfaction. Therefore, we propose the following hypotheses:

H3: Positive buyer emotions do not mediate the influence of distributive fairness on the buyer's satisfaction.

H4: Positive buyer emotions mediate the influence of procedural fairness on the buyer's satisfaction.

\section{Research model}

Figure 1 presents the research model and proposed hypotheses. Stated simply, we propose that fairness has both a direct effect on satisfaction and an indirect effect only for procedural fairness on satisfaction through positive emotions.

Place Figure 1 about here

\section{METHODOLOGY}

\section{Data collection}

This research used a sample of buyers working in the bio-diagnostic sector in France. This sector offers an appealing setting because of the nature of the relationship between the buyer and the key account manager. The selling process usually entails long-term negotiations to build a unique selling proposition for customers (covering products, services, financial terms, and so on) and persists in providing after-sale services. These suppliers offer their customers significant information about the probable evolution of the sector (e.g., practices, competences, technology). Salespeople consequently serve as the key contact point for buyers, before, during, and after purchase episodes. Because of the complex nature of these services, both salespeople and purchasers are closely involved in the commercial exchange. 
Salespeople are supported, when needed, with the assistance of many product managers who specialize in a specific product line.

The questionnaire for this study was attached to an e-mail sent to active and knowledgeable buyers. Respondents provided their opinions about their firm's relationship with a major supplier of their choice, indicated the duration of the relationship, and specified the frequency of various contact methods.

In all, 220 buyers received invitations to participate in the online web survey. We received 130 usable questionnaires, for a response rate of 59\%. Most respondents were men (62\%), aged between $31-50$ years (58\%), who had worked in small enterprises $(85.3 \%)$ as buyers for at least 6 years $(61.1 \%)$. The questions had been translated from English to French by two native speakers (American and French), using a back-translation process to ensure equivalence across the two languages. A pretest suggested some minor changes to the wording, on the basis of comments by French-speaking experts.

The data collection used existing scales, adapted to this study setting (see Appendix for the items). Distributive and procedural fairness were estimated with items from scales provided by Kumar, Scheer, and Steenkamp, (1995). Positive emotions were measured with the three-item scale by White and Yu (White and Yu 2005), which in turn reflects prior studies of consumption emotions (Liljander and Strandvik 1997) and presents emotions along a continuum, from negative to neutral to positive valence. Other scales simply use a list of adjectives to describe an emotional state. A valence approach is more appropriate for our effort to induce respondents to recall emotions toward a relationship. Finally, to assess satisfaction, we used Cannon and Perreault's (1999) scale. Respondents had to evaluate each item on five-point Likert scales ranging from "not agree at all" (1) to "totally agree" (5).

\section{Measure reliability}


The reliability and validity of the measures were tested using SPSS and AMOS. First to explore the possibility of non-response bias, the responses of early and late respondents were compared using ANOVA. No differences in the mean scores of the variables were found, suggesting that non-response bias is not a major problem.

In accordance with previous studies that validated the scales, we found one dimension for each construct except for the Procedural fairness for which two factors appears. We suppress all the items that did not have good communalities and were not correlated to the others. Only the themes knowledgeability and courteous behavior that corresponds more to the interactional fairness of procedural fairness were kept in this research. The KMO test agrees with these factor solutions, which accounts for more than $50 \%$ of total variance. The reliability of internal consistency was estimated with the alpha of Cronbach's alpha is good.

A confirmatory analysis was then carried out using AMOS and indicates a good convergent validity of the scale insofar as all items have Student's t scores higher than 1.96 and satisfactory goodness-of-fit indices. The results indicated acceptable standardized estimates and t-values; in Table 1, we provide the alpha values and intercorrelations.

Place Table 1 about here

According to the Fornell-Larcker criterion (Fornell and Larcker 1981), a construct is deemed discriminately valid if it shares more variance with its assigned indicators than with other latent variables. In statistical terms, this test compares the square root of AVE with the correlations among latent variables. The results presented in Table 2 demonstrate discriminant validity, since all diagonal elements are greater than the non-diagonal elements in the corresponding rows and columns. 
The measurement model produced the following fit statistics: $\chi^{2}=101.86, \mathrm{df}=65, p$ $<.01, \chi^{2} / \mathrm{df}=1.56$, goodness-of-fit index $(\mathrm{GFI})=.90$, adjusted goodness-of-fit index $(\mathrm{AGFI})$ $=.84$, Tucker-Lewis index $(\mathrm{TLI})=.95$, confirmatory fit index $(\mathrm{CFI})=.96$, root mean residual $(\mathrm{RMR})=.06$, and root mean square error of approximation $(\mathrm{RMSEA})=.06$. Thus it offers a reasonably good representation of the variance-covariance matrix of our measures and can be considered suitable for substantive analysis and interpretation.

\section{Hypotheses tests}

With structural equation modeling, we determined that the final model yielded the following fit statistics: $\chi^{2}=96.00, \mathrm{df}=65, p<.01, \chi^{2} / \mathrm{df}=1.47, \mathrm{GFI}=.91, \mathrm{AGFI}=.85$, TLI $=.96, \mathrm{CFI}=.97, \mathrm{RMR}=.06$, and RMSEA $=.06$. The model thus provides an acceptable representation of the data. In Table 3, we present the hypotheses tests and results. To address the mediating role of positive emotions, we followed the procedure proposed by Baron and Kenny (1986). That is, we compared the proposed framework against two competing models: a non-mediated model (M2), from which we excluded positive emotions, and a saturated model (M3) that featured all possible causal paths.

Place Table 3 about here

Baron and Kenny (1986) propose four conditions that must be satisfied to establish mediation. First, researchers must establish that there is an effect that can be mediated, by demonstrating that the independent variables (distributive and procedural fairness) relate 
significantly to the outcome (satisfaction). Our results confirm that distributive fairness and procedural fairness both relate significantly to satisfaction. Second, the independent variables (distributive and procedural fairness) must relate significantly to the hypothesized mediating variable (positive emotions). We find that distributive and procedural fairness is significantly associated with positive emotions. That is, positive emotions mediate the path from procedural and distributive fairness to satisfaction.

Third, we must demonstrate that the hypothesized mediating variables (positive emotions) significantly affect the outcome variable (satisfaction), as is the case in our study, because positive emotions have a significant impact on satisfaction.

Fourth, we evaluated the nature of the mediation by examining the effect of the hypothesized mediating variable (positive emotions) on the relations between exogenous (distributive and procedural fairness) and endogenous (satisfaction) variables. To do so, we compared the results for the non-mediated and the saturated models. Overall, the results indicate that positive emotions do not mediate the impact of distributive fairness on satisfaction, as hypothesized, but partially mediate the impact of procedural fairness on satisfaction (i.e., the path between these variables becomes weaker when positive emotions are included).

\section{RESULTS AND DISCUSSION}

Regarding the mediating effect of positive emotions, our results offer support for the proposed relationships. The proposed model assumes that positive emotions mediate the effects of procedural fairness on satisfaction, whereas only partial meditation arose between procedural fairness and satisfaction. As proposed, however, distributive fairness is not mediated by positive emotions in its effect on satisfaction.

Thus, fairness does offer a lens through which the effects of cognitive and emotional evaluations can be understood when individuals participate in organizational buying roles. In 
particular, distributive fairness arises from a purely rational evaluation of the exchange relationship and is not shaped by the emotional reactions of exchange partners. This outcome component directly affects satisfaction and does not elicit emotional reactions. We posit that distributive fairness, which is rooted in cognitive evaluations of relationships, is fundamentally dependent on rational forces.

In contrast, the impact of procedural fairness is partially mediated by positive emotions. This form thus affects satisfaction directly and indirectly through positive emotions, supporting our hypothesis regarding the moderating effect of emotions.

Together, the two main results suggest that the two components of fairness are significant drivers of customer satisfaction but with strongly divergent effects: Distributive fairness only operates directly; procedural fairness has both direct and indirect effects through positive emotions. That is, the rational outcomes derived from a relationship directly drive customer satisfaction, but the pathways by which these outcomes emerge is doubly important. The procedural component of fairness both explains satisfaction and determines the emotions B2B customers feel, and it thus determines their level of satisfaction.

These findings are important for several reasons. First, our results are consistent with recent research that suggests emotions are key mediators of reactions to perceived fairness, along with attributions. Thus, we extend Chebat and Slusarczyk's (2005) and Schoefer and Ennew's (2005) contributions by showing that positive emotions partially mediate the relationship between perceived fairness and buyer satisfaction. This partial mediation may be a function of the B2B setting in which we conducted our study. As previously mentioned, prior research has focused on the individual roles of fairness and emotion on buyer satisfaction. This study is the first to demonstrate how fairness perceptions and emotions operate on B2B buyer satisfaction; by doing so, this study offers additional insights into the determinants of customer satisfaction. 
Our findings also contribute to relationship marketing literature by documenting how salespersons can enhance relationships. Business buyers' positive emotions and satisfaction depend on their fairness perceptions, but only with regard to procedural fairness. These findings are consistent with existing literature that suggests procedural fairness is more important than distributive fairness for satisfaction. Consequently, economic rewards that flow from the relationship may be important, but the way the sale is realized is an even more powerful driver of customer satisfaction, as we demonstrate with this study.

In turn, firms might adopt several means to ensure that customers perceive "fair" treatment. Procedural fairness largely determines how customers assess relationships; to be perceived as a fair partner, the supplier therefore must develop fair procedures and policies. More than the output, this process by which buyers acquire products and services can aid in establishing a long-term relationship. We therefore recommend that firms demonstrate an effective understanding of the supplier's environment and train their key account managers to exhibit only courteous attitudes toward buyers.

In addition to high quality service, sellers must ensure that buyers are treated the same way (e.g., unbiased information, identical procedures, flexibility), as well as with courtesy and respect. Because such procedures are executed by salespeople and other customer-facing personnel, firms must carefully instill the concept of customer satisfaction among these employees and train them in the proper delivery of service procedures. Formal training programs, well-established procedures, and ongoing constructive feedback can help ensure that employees, and thus the firm overall, deliver processes that will invoke perceptions of fairness.

Although the positive emotional responses derived from perceptions of the fairness of the exchange influence satisfaction judgments, their effect is weaker than the direct effect of procedural fairness on satisfaction, though still stronger than the direct effect of distributive 
fairness. This difference is not unimportant. As Ramaseshan, Rabbanee, and Tan Hsin Hui (2013) explain it, relationship equity is of primary importance in B2B settings and salespeople should be ready and flexible to provide customization opportunities in all senses, especially in the way they interact with the buyer. With this finding, our study reiterates the services marketing literature mandate that "emotions should conceptually be included [into service satisfaction models] and combined with cognitive evaluations of service" (Liljander and Strandvik 1997, , p. 168). We know that some drivers of customer emotion in services such as the extend of employee smiling and the authenticity of the emotional labor display (HennigThurau et al. 2006). This knowledge can be transposed to sales but we can go further. As Smith and Bolton (2002, , p. 19) suggest, frontline service employees should be trained to “decode emotional cues ... and to offer customized recovery efforts to customers who exhibit negative emotional cues." We posit that salespeople could correct, or even avoid, failed service encounters in real time by more effectively selling the way the buyer wants to buy. A recommendation of this study is then to select salespeople that have a high emotional intelligence (Delcourt et al. 2013). Alternatively, companies could train salespeople to recognize and respond to emotions in order to generate positive emotion and drive customer satisfaction. The stake in BtoB - where the sales team interacts with the buying team - is to understand the development of collective emotional intelligence and how it impacts the relation and in particular individual and collective emotion.

Finally, when managers seek to understand and effectively apply the results of customer satisfaction surveys, this study suggests it is necessary to control explicitly for perceived fairness and emotions. While the Net Promoter Score has become widely accepted by businesses as a metric for understanding the depth of satisfaction (Kristensen and Eskildsen 2014), this study provides evidence that a different approach may be needed. When seeking to understand why customers are (dis)satisfied, managers must consider both process 
as procedural fairness and product as distributive fairness. As Tanner (1998) found in a study of organizational buyers, those who are dissatisfied with the purchase process are more likely to seek a bigger role in the next process, irrespective of product satisfaction. While we've long known that satisfaction with one purchase influences the next, those results combined with our study suggests not only that procedural fairness is more important but also how it can affect future decisions. Thus, our work provides significant insight into account management strategy, as salespeople and managers now have direction into how to set up not only stronger satisfaction but also more favorable buying centers.

\section{Limitations and further research}

Although this research sheds light on important issues, several limitations must be noted. First, the data we used to assess the proposed framework came from buyers operating in a single industry that is involved in highly complex purchases. This setting inevitably restricts the generalizability of our findings. Cross-validation in other contexts, such as commodities, services, and other product forms and purchasing contexts, would be required to broaden our understanding how fairness and emotions affect buyer satisfaction.

Second, our study underlines the importance of people and the procedural fairness of the exchange without examining the nature of the channel used by the salesperson. Looking at the impact of diverse nature of contact (email, telephone...) point on customer's emotion is an important track of research because of the (in)ability to gauge emotional responses to selling activities.

Third, we limit our analysis to a positive emotion and the distributive and procedural dimensions of fairness. Additional research could determine how different specific emotions also affect satisfaction.

Fourth, our model proposes a specific pattern of linear relationships between several variables. As suggested by Casado-Diaz, Mas-Ruis and Kasper (2007), the relationship 
between the variables we analyze might not be simple or straightforward. For example, with our temporal measure, we derived the mediating model post hoc; an in-situ study might uncover a more iterative relationship, to evaluate events, identify the emotions that result, and recognize the progression of additional events from a perspective that could alter the outcome. If a buyer is happy (emotion) and satisfied (cognition) following an interaction, the next interaction likely differs from one that follows an encounter that left the buyer unhappy and dissatisfied. We adopt a holistic view (Jüttner et al. 2013) rather than an additive view because relationships and perceptions of satisfaction do not appear to be additive across interactions. However, previous encounters influence people's anticipation of the nature of future encounters and their behaviors within those encounters, which seemingly must affect perceptions of fairness and emotional responses. This study establishes a foundation for further investigations of this question.

Rather than our valence-based measure of emotions, another measurement approach could acknowledge the idiosyncratic elements of specific emotions (e.g., pleasure, happiness). With this approach, different emotions have distinct impacts on satisfaction, so studying them might provide insights into the specific antecedents, phenomenology, and consequences of different emotions. Our conceptual model could be revised to include satisfaction and relationship concepts, such as loyalty, commitment, and trust ; for example, using the work of Yu and Dean (2001).

Finally, we gather static emotions in a dyad; without longitudinal data that allow for some dynamism, we know little about what factors influence the course of a relationship. We propose that if buyers feel positive emotions during service delivery, they might be more patient with the firm, even after a service failure. Further research should test this prediction.

As noted, because we gather static emotions in a dyad, future research should also consider disaggregating the buying center. Perspectives of process and outcomes vary by roles 
in the buying center (e.g. Tanner 1996) but this study was limited to a single contact. Future work should examine the buying center over time to discern the impact of emotions, perceptions of fairness, and other important variables related to customer satisfaction.

\section{Conclusion}

This study makes several important contributions to the understanding of customer satisfaction in a B2B setting. We demonstrate that positive emotions are important in understanding the effects of procedural fairness, a cognitive evaluation that is very important in determining satisfaction. Further, we demonstrate that positive emotions do not mediate evaluations regarding distributive fairness. These findings highlight the importance of salespeople and managerial policies that can enhance procedural fairness evaluations in order to lead to more positive emotions and higher customer satisfaction.

Not only do these findings have practical implications for managing customer relationships and measuring satisfaction, the theoretical contributions are also important. This study offers the first look into the relative importance of both forms of fairness, as well as the first to tease apart the cognitive and emotional dimensions of customer evaluations in a B2B setting. While there is still much work to be done, this study offers a solid foundation for future study of cognition and emotion in organizational buying. 


\section{REFERENCES}

Andersen, Poul Houman, and Rajesh Kumar. 2006. Emotions, trust and relationship development in business relationships: A conceptual model for buyer-seller dyads. Industrial Marketing Management 35 (4):522-535.

Andreassen, Tor Wallin. 2000. Antecedents to satisfaction with service recovery. European Journal of Marketing 34 (1/2):156-175.

Babin, Barry J, and Mitch Griffin. 1998. The nature of satisfaction: an updated examination and analysis. Journal of Business research 41 (2):127-136.

Bagozzi, Richard P. 2006. The role of social and self-conscious emotions in the regulation of business-to-business relationships in salesperson-customer interactions. Journal of Business \& Industrial Marketing 21 (7):453-457.

Baron, Reuben M., and David A. Kenny. 1986. The Moderator-Mediator Variable Distinction in Social Psychological Research: Conceptual, Strategic, and Statistical Considerations. Journal of Personality and Social Psychology 51 (6):1173-1182.

Brown, James R, Anthony T Cobb, and Robert F Lusch. 2006. The roles played by interorganizational contracts and justice in marketing channel relationships. Journal of Business research 59 (2):166-175.

Cannon, Joseph P., and William D. Perreault. 1999. Buyer-seller relationships in business markets. Journal of Marketing Research 36 (4):439-460.

Casado-Díaz, Ana B, Francisco J Más-Ruiz, and Hans Kasper. 2007. Explaining satisfaction in double deviation scenarios: the effects of anger and distributive justice. International Journal of Bank Marketing 25 (5):292-314.

Chebat, Jean-Charles, and Witold Slusarczyk. 2005. How emotions mediate the effects of perceived justice on loyalty in service recovery situations: an empirical study. Journal of Business Research 58 (5):664-673.

Clemmer, Elizabeth C. 1993. An investigation into the relationship of fairness and customer satisfaction with services. In Justice in the workplace: Approaching fairness in human resource management, edited by R. Cropanzano. NJ: Erlbaum: ed. Hillsdale.

Dayan, Mumin, Hussein A Hassan Al-Tamimi, and Amar Lo Elhadji. 2008. Perceived justice and customer loyalty in the retail banking sector in the UAE. Journal of Financial Services Marketing 12 (4):320-330.

Delcourt, Cécile, Dwayne D Gremler, Allard CR van Riel, and Marcel van Birgelen. 2013. Effects of perceived employee emotional competence on customer satisfaction and loyalty: The mediating role of rapport. Journal of Service Management 24 (1):5-24.

Donada, Carole, and Gwenaëlle Nogatchewsky. 2009. Emotions in outsourcing. An empirical study in the hotel industry. International Journal of Hospitality Management 28 (3):367-373.

Duffy, Rachel, Andrew Fearne, Sue Hornibrook, Karise Hutchinson, and Andrea Reid. 2013. Engaging suppliers in CRM: The role of justice in buyer-supplier relationships. International Journal of Information Management 33 (1):20-27.

Dwyer, Robert F., Paul H. Schurr, and Sejo Oh. 1987. Developing buyer-seller relationships. Journal of Marketing 51 (2):11-27.

Erevelles, Sunil, and Nobuyuki Fukawa. 2013. The Role of Affect in Personal Selling and Sales Management. Journal of Personal Selling and Sales Management 33 (1):7-24.

Ford, D. 1982. The development of buyer-seller relationships in industrial markets. In International marketing and purchasing of industrial goods: An interaction approach, edited by H. Håkansson: John Willey \& Sons. 
Fornell, Claes, and David F. Larcker. 1981. Evaluating structural equation models with unobservable variables and measurement errors. Journal of Marketing Research 18 (2):39-50.

Goodwin, Cathy, and Ivan Ross. 1992. Consumer responses to service failures: influence of procedural and interactional fairness perceptions. Journal of Business research 25 (2):149-163.

Håkansson, Håkan. 1982. International marketing and purchasing of industrial goods: An interaction approach. New York: John Willey \& Sons.

Hegtvedt, Karen A. 1990. The effects of relationship structure on emotional responses to inequity. Social Psychology Quarterly 53 (3):214-228.

Hegtvedt, Karen A, and Caitlin Killian. 1999. Fairness and emotions: Reactions to the process and outcomes of negotiations. Social Forces 78 (1):269-302.

Hennig-Thurau, Thorsten, Markus Groth, Michael Paul, and Dwayne D Gremler. 2006. Are all smiles created equal? How emotional contagion and emotional labor affect service relationships. Journal of Marketing 70 (3):58-73.

Homans, George Caspar. 1974. Social Behavior: Its Elementary Forms. New York: Harcourt Brace.

Hoppner, Jessica J., David A. Griffith, and ChangSeob Yeo. 2014. The intertwined relationships of power, justice and dependence. European Journal of Marketing 48 (9/10):1690-1708.

Humphreys, Michael A, and Michael R Williams. 1996. Exploring the relative effects of salesperson interpersonal process attributes and technical product attributes on customer satisfaction. Journal of Personal Selling \& Sales Management 16 (3):47-57.

Jap, Sandy D. 2001. "Pie sharing" in complex collaboration contexts. Journal of Marketing Research 38 (1):86-99.

Jüttner, Uta, Dorothea Schaffner, Katharina Windler, and Stan Maklan. 2013. Customer service experiences: Developing and applying a sequentialincident laddering technique. European Journal of Marketing 47 (5/6):738-769.

Kim, Young "Sally" K., and Amy K. Smith. 2005. Crime and Punishment Examining Customers' Responses to Service Organizations' Penalties. Journal of Service Research 8 (2):162-180.

Kristensen, Kai, and Jacob Eskildsen. 2014. Is the NPS a trustworthy performance measure? The TQM Journal 26 (2):202-214.

Kumar, Nirmalya, Lisa K. Scheer, and Jan-Benedict E.M. Steenkamp. 1995. The effects of supplier fairness on vulnerable resellers. Journal of Marketing Research 32 (1):54-65.

Liljander, Veronica, and Tore Strandvik. 1997. Emotions in service satisfaction. International Journal of Service Industry Management 8 (2):148-169.

Oliver, Richard L. 1980. A cognitive model of the antecedents and consequences of satisfaction decisions. Journal of Marketing Research 17 (4):460-469.

Ramaseshan, Balasubramanian, Fazlul K Rabbanee, and Laine Tan Hsin Hui. 2013. Effects of customer equity drivers on customer loyalty in B2B context. Journal of Business \& Industrial Marketing 28 (4):335-346.

Saxby, Carl L, Peter K Tat, and Jane Thompson Johansen. 2000. Measuring consumer perceptions of procedural justice in a complaint context. Journal of Consumer Affairs 34 (2):204-216.

Scher, Steven J., and David Heise. 1993. Affect and the perception of unfairness. Advances in Group Process 10:223-252.

Schoefer, Klaus, and Christine Ennew. 2005. The impact of perceived justice on consumers' emotional responses to service complaint experiences. Journal of Services Marketing 19 (5):261-270. 
Smith, Amy K, and Ruth N Bolton. 2002. The effect of customers' emotional responses to service failures on their recovery effort evaluations and satisfaction judgments. Journal of the Academy of Marketing Science 30 (1):5-23.

Sprecher, Susan. 1992. How men and women expect to feel and behave in response to inequity in close relationships. Social Psychology Quarterly 55 (1):57-69.

Tähtinen, Jaana, and Keith J. Blois. 2011. The involvement and influence of emotions in problematic business relationships. Industrial Marketing Management 40 (6):907-918.

Tanner, John F. 1996. Buyer perceptions of the purchase process and its effect on customer satisfaction. Industrial Marketing Management 25 (2):125-133.

Tanner, John F. 1999. Organizational buying theories: A bridge to relationships theory. Industrial Marketing Management 28 (3):245-255.

Tanner, John F Jr. 1998. Users' role in the purchase: their influence, satisfaction and desire to participate in the next purchase. Journal of Business \& Industrial Marketing 13 (6):479-491.

Tax, Stephen S., Stephen W. Brown, and Murali Chandrashekaran. 1998. Customer evaluations of service complaint experiences: implications for relationship marketing. The Journal of Marketing 62 (2):60-76.

Vidal, David. 2014. Eye for an eye: Examining retaliation in business-to-business relationships. European Journal of Marketing 48 (1/2):47-67.

Voss, B. 1990. Cutting through the clutter. Sales and Marketing Management February:19-20.

Wang, Sijun, and Lenard C. Huff. 2007. Explaining buyers' responses to sellers' violation of trust. European Journal of Marketing 41 (9/10):1033-1052.

Westbrook, Robert A. 1987. Product/consumption-based affective responses and postpurchase processes. Journal of Marketing Research 24 (3):258-270.

Westbrook, Robert A, and Richard L Oliver. 1991. The dimensionality of consumption emotion patterns and consumer satisfaction. Journal of Consumer Research 18 (1):8491.

White, Christopher, and Yi-Ting Yu. 2005. Satisfaction emotions and consumer behavioral intentions. Journal of Services Marketing 19 (6):411-420.

$\mathrm{Yu}$, Yi-Ting, and Alison Dean. 2001. The contribution of emotional satisfaction to consumer loyalty. International Journal of Service Industry Management 12 (3):234-250. 
Table 1: Reliability and intercorrelations of variables

\begin{tabular}{lccllll}
\hline & Mean & SD & 1 & 2 & 3 & 4 \\
\hline 1. Distributive Fairness & 8.85 & 2.41 & .68 & & & \\
\hline 2. Procedural Fairness & 15.76 & 3.13 & .11 & .84 & & \\
\hline 3. Positive emotions & 14.67 & 3.45 & $.20^{*}$ & $.69^{* *}$ & .89 & \\
\hline 4. Satisfaction & 11.62 & 2.73 & $.22^{*}$ & $.62^{* *}$ & $.68^{* *}$ & .89 \\
\hline
\end{tabular}

** Correlation is significant at the 0.01 level.

Table 2: Psychometric Properties of the Measurement Model

\begin{tabular}{|c|c|c|c|c|c|c|c|c|}
\hline Constructs/Items & $\begin{array}{c}\text { Original } \\
\text { Sample }\end{array}$ & $\begin{array}{c}\text { Standard } \\
\text { Error }\end{array}$ & t-value & p-value & $\alpha$ & CR & AVE & $\begin{array}{l}\text { Root } \\
\text { AVE } \\
\end{array}$ \\
\hline \multicolumn{5}{|c|}{ Distributive Fairness } & .73 & .75 & .46 & .68 \\
\hline DisFair1 & .63 & .16 & 5.09 & .000 & & & & \\
\hline DisFair2 & .74 & .24 & 5.15 & .000 & & & & \\
\hline DisFair3 & .65 & .24 & 5.09 & .000 & & & & \\
\hline \multicolumn{5}{|c|}{ Procedural Fairness } & .85 & .84 & .59 & .77 \\
\hline ProcFair1 & .50 & .12 & 5.98 & .000 & & & & \\
\hline ProcFair2 & .65 & .09 & 8.48 & .000 & & & & \\
\hline ProcFair3 & .94 & .15 & 14.36 & .000 & & & & \\
\hline ProcFair4 & .90 & .15 & 8.48 & .000 & & & & \\
\hline \multicolumn{5}{|c|}{ Positive emotions } & .88 & .89 & .68 & .82 \\
\hline PosEmo1 & .83 & .07 & 13.00 & .000 & & & & \\
\hline PosEmo2 & .95 & .08 & 13.00 & .000 & & & & \\
\hline PosEmo3 & .90 & .05 & 11.72 & .000 & & & & \\
\hline PosEmo4 & .56 & .08 & 6.92 & & & & & \\
\hline \multicolumn{5}{|c|}{ Satisfaction } & .92 & .89 & .74 & .86 \\
\hline Sat1 & .69 & .06 & 10.70 & .000 & & & & \\
\hline Sat2 & .94 & .05 & 17.70 & .000 & & & & \\
\hline Sat3 & .93 & .13 & 10.70 & .000 & & & & \\
\hline
\end{tabular}

Table 3: Hypotheses tests

\begin{tabular}{|c|c|c|c|c|c|}
\hline Hypotheses & \multicolumn{2}{|c|}{ M2 (non-mediated) } & \multicolumn{2}{|c|}{ M3 (saturated) } & \multirow[t]{2}{*}{ Results } \\
\hline & $\begin{array}{c}S d \\
\text { Coef. }\end{array}$ & $t$-value & Sd Coef. & t-value & \\
\hline \multirow{2}{*}{$\begin{array}{l}\text { H1 Distributive fairness } \rightarrow \text { Satisfaction } \\
\text { H2 Procedural fairness } \rightarrow \text { Satisfaction }\end{array}$} & 23 & 2.58 & .18 & 2.14 & \multirow{2}{*}{$\begin{array}{l}\text { No mediation } \\
\text { Partial } \\
\text { mediation }\end{array}$} \\
\hline & .31 & 6.74 & .33 & 3.21 & \\
\hline H3 Distributive fairness $\rightarrow$ Positive emotions & - & - & .17 & 2.35 & Not sig. \\
\hline H4 Procedural fairness $\rightarrow$ Positive emotions & - & - & .65 & 7.66 & Sig \\
\hline H5 Positive emotions $\rightarrow$ Satisfaction & - & - & .42 & 4.14 & Sig \\
\hline
\end{tabular}


Figure 1: Research Model

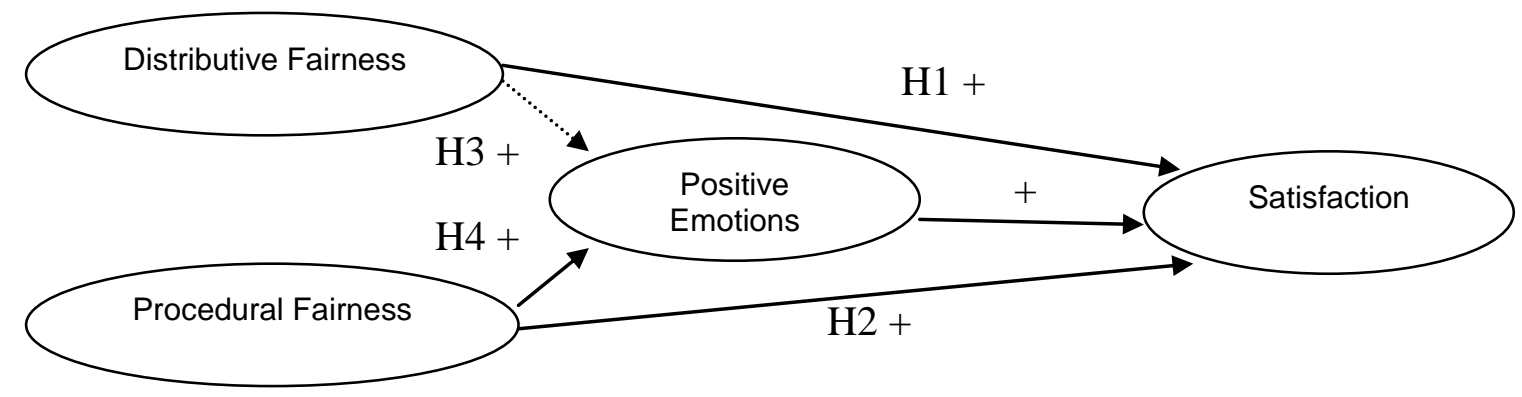




\section{APPENDIX: List of questionnaire items}

\section{Distributive Fairness}

How fair are your firm's outcomes and earnings compared to:

The effort and investment that we have made lo support the supplier's line (suppressed)

The roles and responsibilities the supplier assigns to your organization (suppressed)

What other dealers in our industry earn

What the supplier earns from sales through our dealership

The contributions your company makes to this supplier's marketing effort

\section{Procedural Fairness}

In relationships with their dealers, the supplier and their personnel

Promote bilateral communication with the dealers (suppressed)

Have many exchanges with the dealer (suppressed)

Do not discriminate but rather treat all dealers similarly (suppressed)

Apply consistent policies and decision making procedures across all dealers (suppressed)

Sometimes alter their policies in response to dealer objections (suppressed)

Seriously consider a dealer's objections to the supplier's policies and programs (suppressed)

Seldom explain their decisions to dealers (R) (suppressed)

Provide valid reasons for any changes in policies affecting the dealers (suppressed)

Are knowledgeable about the local situations faced by the dealers

Take pains to leant the local conditions under which the dealers operate

Treat the dealers with respect

Are polite and well-mannered 


\section{Emotions}

How do you feel, following the interaction with the salesperson?

Happy of this interaction

Hopeful in the future

Positive

Agreeably surprised

\section{Satisfaction}

Our firm regrets the decision to do business with this supplier (R) (Suppressed)

Overall, I am very satisfied with what this supplier does for us

I am very pleased with what this supplier does for us

Our firm is completely happy with this supplier

If we had to do il all over again, we would still choose to use this supplier (Suppressed) 


\section{Practitioner's summary :}

The research show that economic rewards that flow from the relationship may be important, but the way the sale is realized is an even more powerful driver of customer satisfaction in Bto-B. Procedural fairness largely determines how customers assess relationships; to be perceived as a fair partner, the supplier therefore must develop fair procedures and policies. In turn, firms might adopt several means to ensure that customers perceive "fair" treatment. More than the output, this process by which buyers acquire products and services can aid in establishing a long-term relationship. We therefore recommend that firms demonstrate an effective understanding of the supplier's environment and train their key account managers to exhibit only courteous attitudes toward buyers.

In addition to high quality service, sellers must ensure that buyers are treated the same way as well as with courtesy and respect. Because such procedures are executed by salespeople and other customer-facing personnel, firms must carefully instill the concept of customer satisfaction among these employees and train them in the proper delivery of service procedures. Formal training programs, well-established procedures, and ongoing constructive feedback can help ensure that employees, and thus the firm overall, deliver processes that will invoke perceptions of fairness.

Although the positive emotional responses derived from perceptions of the fairness of the exchange influence satisfaction judgments, their effect is weaker than the direct effect of procedural fairness on satisfaction, though still stronger than the direct effect of distributive fairness. This difference is not unimportant. As Ramaseshan, Rabbanee, and Tan Hsin Hui (2013) explain it, relationship equity is of primary importance in B2B settings and salespeople should be ready and flexible to provide customization opportunities in all senses, especially in the way they interact with the buyer. 
This study underlines that as frontline service employees, salespeople in B-to-B should be trained to decode emotional cues. A recommendation of this study is then to select salespeople that have a high emotional intelligence. Alternatively, companies could train salespeople to recognize and respond to emotions in order to generate positive emotion and drive customer satisfaction. The stake in BtoB - where the sales team interacts with the buying team - is to understand the development of collective emotional intelligence and how it impacts the relation and in particular individual and collective emotion.

Finally, when managers seek to understand and effectively apply the results of customer satisfaction surveys, this study suggests it is necessary to control explicitly for perceived fairness and emotions. While the Net Promoter Score has become widely accepted by businesses as a metric for understanding the depth of satisfaction, this study provides evidence that a different approach may be needed. When seeking to understand why customers are (dis)satisfied, managers must consider both process as procedural fairness and product as distributive fairness. As Tanner (1998) found in a study of organizational buyers, those who are dissatisfied with the purchase process are more likely to seek a bigger role in the next process, irrespective of product satisfaction. While we've long known that satisfaction with one purchase influences the next, those results combined with our study suggests not only that procedural fairness is more important but also how it can affect future decisions. Thus, our work provides significant insight into account management strategy, as salespeople and managers now have direction into how to set up not only stronger satisfaction but also more favorable buying centers. 